\title{
Cardiovascular and Blood Oxidative Stress Responses to Exercise and Acute Woodsmoke Exposure in Recreationally Active Individuals
}

Cassie M. Williamson-Reisdorph, MS; Kathryn G. Tiemessen, MS; Katie Christison, MS; Shae Gurney, MS; Dylan Richmond, MS; Kesley Wood, BS; Tiffany S. Quindry, BS; Charles L. Dumke, PhD; John C. Quindry, PhD

School of Integrative Physiology and Athletic Training, University of Montana, Missoula, Montana

Introduction-Those who work and recreate outdoors experience woodsmoke exposure during fire season. Exercise during woodsmoke exposure harms the cardiovascular system, but the acute physiologic and biochemical responses are understudied. The purpose of this pilot laboratory-based study was to examine the effect of exercise during woodsmoke exposure on acute indicators of cardiovascular function, including heart rate variability (HRV), pulse wave velocity (PWV), blood pressure (BP), augmentation index (AIx), and blood oxidative stress.

Methods-Ten participants performed 2 moderate-intensity exercise $\left(70 \% \dot{\mathrm{VO}}_{2}\right.$ max $)$ trials (clean air $0 \mu \mathrm{g} \cdot \mathrm{m}^{-3}$, woodsmoke $250 \mu \mathrm{g} \cdot \mathrm{m}^{-3}$ ) in a crossover design. HRV, PWV, BP, AIx, and blood oxidative stress were measured before, after, and $90 \mathrm{~min}$ after exercise for each trial. Blood oxidative stress was quantified through lipid damage (LOOH, 8-ISO), protein damage (3-NT, PC), and antioxidant capacity (TEAC).

Results-A 45-min woodsmoke exposure combined with moderate-intensity exercise did not result in a statistically significant difference in HRV, PWV, BP, AIx, or oxidative stress $(P>0.05)$.

Conclusions-Despite the known deleterious effects of smoke inhalation, moderate-intensity aerobic exercise while exposed to woodsmoke particulate matter $\left(250 \mu \mathrm{g} \cdot \mathrm{m}^{-3}\right)$ did not result in a statistically significant difference in HRV, PWV, or blood oxidative stress in this methodologic context. Although findings do not negate the negative impact of woodsmoke inhalation, additional research approaches are needed to better understand the acute effects of smoke exposure on the cardiovascular system.

Keywords: air pollution, free radicals, antioxidants, autonomic recovery, parasympathetic recovery, arterial stiffness

\section{Introduction}

Smoke inhalation from biomass combustion is a public health problem in the western United States owing to frequent and large-scale wildfires. ${ }^{1}$ Health dangers are associated with biomass particulate matter (PM) inhalation, including airborne particles $\leq 2.5$ microns in diameter $\left(\mathrm{PM}_{2.5}\right)$. Populations affected by $\mathrm{PM}_{2.5}$ include wildland firefighters and those who exercise outside. ${ }^{2}$ Exercise ventilatory rates elevate the inhaled $\mathrm{PM}_{2.5}$

Corresponding author: John C. Quindry, PhD, 32 Campus Drive, 101 McGill Hall, University of Montana, Missoula, MT 59812; e-mail: john. quindry@mso.umt.edu.

Submitted for publication August 2020.

Accepted for publication October 2021. dose, and smoke inhalation dose is proportional to the $\mathrm{PM}_{2.5}$ concentration, duration of exposure, and ventilatory rates associated with activity. ${ }^{3}$ Accordingly, this approach for estimating woodsmoke inhalation doses is currently untested in laboratory assessments where the acute impacts on cardiovascular function can be determined.

Long-term smoke inhalation elevates the risk for cardiovascular mortality by 0.4 to $1.0 \%$ with an incremental increase of only $10 \mu \mathrm{g} \cdot \mathrm{m}^{-3}$ above the mean 24-h $\mathrm{PM}_{2.5}$ concentration. ${ }^{4}$ Furthermore, chronic $\mathrm{PM}_{2.5}$ inhalation is associated with reduced life expectancy and increased rates of cardiovascular disease. ${ }^{4}$ How the long-term consequences of smoke inhalation are reflected by acute physiologic and biochemical responses to smoke 
inhalation is relatively understudied. Preliminary findings in this regard indicate that pathophysiologic mechanisms include perturbations in autonomic dysregulation, mitigated cardiovascular control, systemic inflammation, and oxidative stress. ${ }^{4}$ Cardiovascular and autonomic control can be quantified by heart rate variability (HRV), pulse wave velocity (PWV), and resting blood pressure (BP). HRV is prognostic of cardiovascular health when HRV recovery after physiologic stressors is delayed. ${ }^{5}$ In some experimental context, HRV is reduced by woodsmoke inhalation, suggesting a concomitant decline in autonomic tone. ${ }^{6,7}$ PWV and blood oxidative stress also provide further insight into acute physiologic changes after exercise with woodsmoke exposure.

We examined the effect of exercise on acute woodsmoke inhalation using a laboratory-based pilot investigation. Key dependent variables included metrics of cardiovascular function (HRV, PWV) and a blood oxidative stress panel to gauge associations between woodsmoke inhalation and cardiovascular control. This approach was based on prior investigations that demonstrated physiologic perturbations at $\mathrm{PM}_{2.5}$ inhalation dosages of $250 \mu \mathrm{g} \cdot \mathrm{m}^{-3}$, , 9 or "very unhealthy" according to the air quality index. We hypothesized that moderateintensity exercise during a 45-min woodsmoke exposure at $250 \mu \mathrm{g} \cdot \mathrm{m}^{-3}$ would decrease $\mathrm{HRV}$, elevate PWV, and amplify blood oxidative stress.

\section{Methods}

University of Montana institutional review board and participant informed consent was obtained before data collection. Inclusion criteria dictated a $\dot{\mathrm{V}}_{2}$ max of $\geq 40.0$ $\mathrm{mL} \cdot \mathrm{kg}^{-1} \cdot \mathrm{min}^{-1}$. The presence of limiting orthopedic problems, smoking (previous $6 \mathrm{mo}$ ), or diagnosed cardiovascular, pulmonary, or metabolic diseases (determined by the physical activity readiness questionnaire) resulted in exclusion from the study. ${ }^{10}$

The study used a crossover design. Data collection started between 0600 and 0900 on 3 occasions with a minimum of $7 \mathrm{~d}$ separating visits to allow for a wash-out period after smoke exposure. Participants fasted for $10 \mathrm{~h}$, abstained from alcohol and exercise for $24 \mathrm{~h}$, and avoided caffeine for $12 \mathrm{~h}$ before testing. The first laboratory visit consisted of study orientation, body composition measurements, and a $\dot{\mathrm{V}}_{2}$ max cycling test. The 2 exposure trials were performed in filtered air $\left(0 \mu \mathrm{g} \cdot \mathrm{m}^{-3}\right)$ and woodsmoke $\left(250 \mu \mathrm{g} \cdot \mathrm{m}^{-3}\right)$ during $45 \mathrm{~min}$ of cycling at $70 \% \dot{\mathrm{V}}_{2}$ max. Measurements of HRV, PWV, augmentation index (AIx), BP, pulmonary function (PF), and blood sampling for oxidative stress were conducted before (PRE), immediately after (IPE), and $90 \mathrm{~min}$ postexercise (90-P) (Figure 1). The battery was completed within 30 to $45 \mathrm{~min}$. All IPE measurements were collected within 45 min of the cessation of exercise, and all 90-P measurements were collected between 90 and $120 \mathrm{~min}$ after completion of exercise.

Body composition was measured via hydrostatic weighing (Exertech, Dresbach, MN). Values were corrected for residual lung volume (residual lung volume $=(0.01115 \cdot$ Age $)+(0.019 \cdot$ Height $)-2.24)$ and body volume estimates were converted to percent body fat using the Siri Equation. ${ }^{11}$ The $\dot{\mathrm{V}} \mathrm{O}_{2}$ max test was performed on a cycle ergometer (Velotron, Spearfish, SD) after a 5-min warmup at $50 \mathrm{~W}$ and transitioned into a ramp protocol (resistance $+1 \mathrm{~W} / 2$ s until $<60 \mathrm{rpm}$ occurred). Expired gas was sampled using indirect calorimetry (Cosmed Quark CPET, Concord, CA).

Exposure trials were conducted at the inhalation and pulmonary physiology core at the Center for Environmental Health Sciences at the University of Montana. Fires were generated using an in-line inhalation system woodstove stoked with western larch (Larix occidentalis Nutt). Fires were prepared 30 min before exercise using 1 $\mathrm{kg}$ of wood and kindling and were stoked with $300 \mathrm{~g}$ of wood every $15 \mathrm{~min}$ throughout the trial.

Participants kept a nutritional log for $24 \mathrm{~h}$ before each session and repeated dietary practices for each trial. Participants were exposed to filtered air $\left(0 \mu \mathrm{g} \cdot \mathrm{m}^{-3}\right)$ and woodsmoke $\left(250 \mu \mathrm{g} \cdot \mathrm{m}^{-3}\right)$ in a crossover design while exercising. Exposures were alternated and conducted in a blinded fashion. A third-party core-laboratory researcher was aware of the exposure condition until the conclusion of data collection. $\mathrm{PM}_{2.5}$ levels were monitored continuously, and woodsmoke concentrations were maintained with $\mathrm{PM}_{2.5}$ monitors (DustTrak, TSI, Model 8530, Shoreview, MN). Participants breathed through a modified mask to deliver woodsmoke. Exercise consisted of cycle ergometry at $70 \% \dot{\mathrm{VO}}_{2}$ max (Monark 828E, Langley, WA) for $45 \mathrm{~min}$. HRV, PWV, AIx, BP, PF, and blood samples were collected at PRE, IPE, and 90-P. PRE and 90-P measurements were collected in the following order: HRV, PWV, AIx, BP, PF, and blood samples. IPE measurements were collected in the same order, except the blood samples were taken before HRV measurements and immediately after the cessation of exercise. When collecting IPE and 90-P measurements, researchers were blind to the pre-exercise values until the time of analysis.

HRV indices included the root mean square of successive differences (RMSSD), high frequency (HF), low frequency (LF), and the ratio LF:HF, as based on established methods. ${ }^{5,12}$ Participants tested in a quiet, dimly lit room in supine position on an examination table. ECG electrodes were placed in a modified limb lead configuration using an iWorx system (iWorx, Dover, NH). Three 


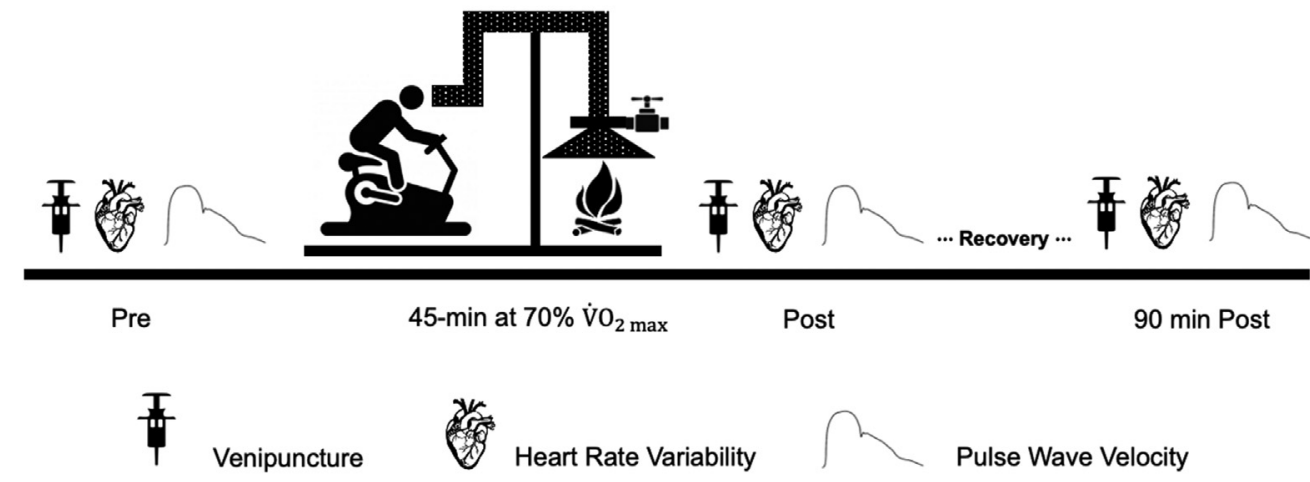

Figure 1. Experimental design. A crossover design was used for the investigation to examine differences in cardiovascular and oxidative responses with exposure to either filtered air $\left(0 \mu \mathrm{g} \cdot \mathrm{m}^{-3}\right)$ or woodsmoke $\left(250 \mu \mathrm{g} \cdot \mathrm{m}^{-3}\right)$.

10-min recordings were obtained (PRE, IPE, and 90-P), and the last 5-min segment was used for analysis on Kubios software (Kubios, V 2.2, Joensuu, Finland). As an a priori decision, all $4 \mathrm{HRV}$ metrics would need to be altered by exposure to be considered physiologically significant, owing to the interrelational nature of the assessment.

PWV, AIx, and BP were obtained using the SphygmoCor XCEL device (Atcor Medical, Sydney, Australia) after $10 \mathrm{~min}$ of supine rest. Right side measurements were recorded until 3 values were obtained within 0.5 $\mathrm{m} \cdot \mathrm{s}^{-1}$. The femoral cuff was placed around the upper thigh, and carotid pulse was identified using applanation tonometry. PWV between the carotid and femoral arteries was calculated based on the arterial stiffness formula: PWV=distance (m)/transit time (s).

Blood was collected via venipuncture through an antecubital vein. Samples were collected in 10-mL heparinized tubes and immediately centrifuged at $1500 \mathrm{rpm}$ for $15 \mathrm{~min}$ at $4^{\circ} \mathrm{C}$, aliquoted, and stored at $-80^{\circ} \mathrm{C}$ until assayed.

A panel of blood oxidative stress markers was measured for lipid (lipid hydroperoxides, LOOH, 8-isoprostane, 8-ISO) and protein damage (protein carbonyls, PC and 3-nitrotyrosine, 3-NT). Trolox equivalent antioxidant capacity (TEAC) was used as a marker of antioxidant status. Samples were subjected to a single freeze-thaw cycle and were kept on ice in the dark to prevent redox alterations.

TEAC assays were performed to measure antioxidant scavenging of 2,2á-azinobis-(3-ethyl-benzo-thiazoline-6sulfonic acid) radical anions using a colorimetric reaction. Calculated TEAC values from unknown samples were compared to standard reactions with the water-soluble vitamin $\mathrm{E}$ analogue Trolox. ${ }^{13}$
Plasma LOOH were measured by the ferrous oxidation-xylenol orange assay using absorbance spectroscopy at a wavelength of $595 \mathrm{~nm}$ and compared with cumene hydroperoxide standards. ${ }^{14}$ 8-ISO was assessed using a commercially available enzyme-linked immunosorbent assay kit according to the manufacturer's guidelines (Cayman Chemical, Ann Arbor, MI).

Oxidative protein damage was quantified using absorbance spectroscopy according to the established methods of Bradford, ${ }^{15}$ followed by a commercially available enzyme-linked immunosorbent assay kit (Enzo Life Sciences, Farmingdale, NY and Cell Biolabs INC, San Diego, CA).

$\mathrm{PF}$, a secondary variable, was assessed by forced vital capacity (FVC) and maximal voluntary ventilation (MVV, performed for $12 \mathrm{~s}$ ) tests using a spirometer (MIR Spirobank, Elicott City, MD), with participants tested in the seated position. Participants were provided with verbal encouragement during PF tests. Data were analyzed using the WINSPIRO Pro software (Version 7.8, Ellicott City, MD).

A series of exposure $\times$ time repeated-measures analysis of variance with a Bonferroni correction was performed to compare the differences in mean values. The general linear model function was used in statistical software (V.25.0, SPSS Inc., Chicago, IL) for all analyses. A criterion alpha level of $P \leq 0.05$ was used to determine statistical significance. Data are reported as mean \pm SD. When analyzing $\mathrm{HRV}$, to satisfy the normality assumption, a natural logarithmic transformation was performed on RMSSD, HF, and LF, and these were reported as $\operatorname{lnRMSSD}, \operatorname{lnHF}$, and $\operatorname{lnLF}$ before statistical analysis. The aim of the study was to determine if woodsmoke exposure during moderateintensity exercise results in deleterious effects on variables of cardiovascular function. 


\section{Results}

Ten active individuals (male: $\mathrm{n}=7$, female: $\mathrm{n}=3$ ) completed the study. Participant characteristics are presented in Table 1.

No interaction effect was observed for HR $(P=0.965)$ or recovery of HR $(P=0.784)$. No statistically significant difference was observed in HR during the exposure trials $(P=0.541)$ or during the recovery of HR $(P=0.734)$. HR was elevated similarly during the experimental trials. HR responses across the trial (Table 2), when comparing rest to IPE and 90-P, indicated a time effect whereby IPE was elevated $(P<0.001)$. Average $\mathrm{HR}$ values returned to baseline at $90-\mathrm{P}(P=0.06)$.

HRV was quantified for $\operatorname{lnRMSSD}$, lnHF, lnLF, and LF:HF (Table 2). Analysis of lnRMSSD, $\operatorname{lnHF}, \operatorname{lnLF}$, and the LF:HF ratio indicated no interaction effects (lnRMSSD: $P=0.912$; lnHF: $P=0.148$; lnLF: $P=0.905$; LF:HF: $P=0.109$ ) and no between-trial differences (lnRMSSD: $P=0.685$; lnHF: $P=0.843$; lnLF: $P=0.275$; LF:HF: $P=0.057$ ); however, a main effect of time was observed (lnRMSSD: $P=0.001$; lnHF: $P=0.003$ ), indicating that parasympathetic activity was reduced in response to exercise. A significant reduction occurred at IPE (lnRMSSD: $P=0.016$; lnHF: $P=0.005$ ), with a recovery of both indices by $90-\mathrm{P}(P>0.99)$. InLF demonstrated a time effect $(P=0.039)$. At $90-\mathrm{P}, \operatorname{lnLF}$ was lower than IPE $(P=0.026)$ and pre-exercise values. Finally, examination of the LF:HF ratio indicated no time effect $(P=0.189)$.

Analysis of PWV and AIx (Table 2) indicated no interaction effect (PWV: $P=0.909$; AIx: $P=0.626$ ), trial effect (PWV: $P=0.856$; AIx: $P=0.136$ ), or time effect (PWV: $P=0.975$; AIx: $P=0.192$ ), indicating that these markers were not significantly different. No statistical difference was observed in brachial BP for trial (SBP: $P=0.883$; DBP: $P=0.769$ ) or time (SBP: $P=0.293$; DBP: $P=0.705)$.

Blood oxidative stress (Table 3) analyses indicated no interaction $(P=0.699)$ trial $(P=0.505)$, or time effect $(P=0.711)$ on $\mathrm{PC}$, indicating that the protein damage

Table 1. Participant characteristics

\begin{tabular}{lrrr}
\hline Characteristic & $n=10$ & $\begin{array}{l}\text { Males } \\
(n=7)\end{array}$ & \multicolumn{1}{l}{$\begin{array}{l}\text { Females } \\
(n=3)\end{array}$} \\
\hline Age $(\mathrm{y})$ & $30 \pm 11$ & $31 \pm 13$ & $27 \pm 2$ \\
Height $(\mathrm{cm})$ & $176 \pm 9$ & $182 \pm 5$ & $165 \pm 1$ \\
Weight $(\mathrm{kg})$ & $76 \pm 12$ & $83 \pm 7$ & $62 \pm 1$ \\
Body fat $(\%)$ & $19 \pm 9$ & $17 \pm 9$ & $24 \pm 7$ \\
$\mathbf{V}_{2}$ max $\left(\mathrm{mL} \cdot \mathrm{kg}^{-1} \cdot \mathrm{min}^{-1}\right)$ & $44 \pm 4$ & $46 \pm 4$ & $41 \pm 1$ \\
\hline
\end{tabular}

Data presented as mean $\pm \mathrm{SD}$.
Table 2. Variables of cardiovascular function

\begin{tabular}{|c|c|c|c|c|}
\hline \multirow[t]{2}{*}{ Marker } & $\begin{array}{l}\text { Filtered } \\
\text { air trial }\end{array}$ & $\begin{array}{l}\text { Woodsmoke } \\
\text { trial }\end{array}$ & \multirow{2}{*}{$\begin{array}{c}\text { Main } \\
\text { effect } \\
P\end{array}$} & \multirow{2}{*}{$\begin{array}{c}\text { Interactior } \\
\text { effect } \\
P\end{array}$} \\
\hline & \multicolumn{2}{|c|}{ Mean $\pm S D$} & & \\
\hline \multicolumn{5}{|c|}{$\begin{array}{l}\text { Heart rate } \\
\quad\left(\text { beats } \cdot \min ^{-1}\right)\end{array}$} \\
\hline PRE & $53 \pm 7$ & $49 \pm 11$ & 0.734 & 0.784 \\
\hline IPE & $68 \pm 9$ & $72 \pm 10$ & & \\
\hline 90-P & $57 \pm 8$ & $55 \pm 9$ & & \\
\hline \multicolumn{5}{|c|}{$\operatorname{lnRMSSD}(\mathrm{ms})$} \\
\hline PRE & $4.3 \pm 0.6$ & $4.3 \pm 0.5$ & 0.685 & 0.912 \\
\hline IPE & $3.6 \pm 0.6$ & $3.6 \pm 0.5$ & & \\
\hline 90-P & $4.2 \pm 0.5$ & $4.3 \pm 0.6$ & & \\
\hline \multicolumn{5}{|c|}{$\operatorname{lnHF}\left(\mathrm{ms}^{2}\right)$} \\
\hline PRE & $7.5 \pm 1.4$ & $7.3 \pm 1.1$ & 0.843 & 0.148 \\
\hline IPE & $6.0 \pm 1.3$ & $5.7 \pm 1.3$ & & \\
\hline 90-P & $7.2 \pm 1.1$ & $7.5 \pm 1.3$ & & \\
\hline \multicolumn{5}{|c|}{$\operatorname{lnLF}\left(\mathrm{ms}^{2}\right)$} \\
\hline PRE & $7.3 \pm 1.2$ & $7.4 \pm 1.2$ & 0.275 & 0.905 \\
\hline IPE & $6.4 \pm 1.2$ & $6.6 \pm 0.9$ & & \\
\hline 90-P & $7.2 \pm 1.1$ & $7.4 \pm 0.9$ & & \\
\hline \multicolumn{5}{|l|}{ LF:HF } \\
\hline PRE & $1.0 \pm 0.5$ & $1.2 \pm 1.0$ & 0.057 & 0.109 \\
\hline IPE & $2.5 \pm 1.8$ & $4.2 \pm 3.6$ & & \\
\hline 90-P & $1.9 \pm 1.6$ & $1.7 \pm 1.3$ & & \\
\hline \multicolumn{5}{|c|}{$\operatorname{PWV}\left(\mathrm{m} \cdot \mathrm{s}^{-1}\right)$} \\
\hline PRE & $5.9 \pm 1.3$ & $5.4 \pm 1.3$ & 0.856 & 0.909 \\
\hline IPE & $5.8 \pm 1.4$ & $5.8 \pm 1.2$ & & \\
\hline 90-P & $6.1 \pm 1.2$ & $6.0 \pm 1.3$ & & \\
\hline \multicolumn{5}{|c|}{$\begin{array}{l}\text { Augmentation } \\
\text { index }(\%)\end{array}$} \\
\hline PRE & $7.3 \pm 5.5$ & $3.6 \pm 8.9$ & 0.136 & 0.626 \\
\hline IPE & $9.2 \pm 12.5$ & $7.7 \pm 8.0$ & & \\
\hline 90-P & $5.7 \pm 3.0$ & $3.6 \pm 9.7$ & & \\
\hline
\end{tabular}

90-P, 90 min postexercise; HF, high frequency; IPE, immediately after exercise; LF, low frequency; PRE, before exercise; PWV, pulse wave velocity; RMSSD, root mean square of successive differences.

marker was not statistically different with exposure or exercise. 3-NT and LOOH data revealed no interaction (3NT: $P=0.784$; LOOH: $P=0.126)$ or time effect (3-NT: $P=0.426$; LOOH: 0.159); however, a main effect for trial was observed (3-NT: $P=0.046$; LOOH: $P=0.011$ ). 8 -ISO demonstrated no interaction effect $(P=0.800)$, trial effect ( $P=0.296)$, or time effect $(P=0.158)$. Antioxidant capacity demonstrated a time effect $(P=0.009)$, but no effect of trial $(P=0.068)$ or interaction effect $(P=0.234)$. TEAC was elevated at IPE $(P=0.002)$ and $90-P(P=0.003)$. Similarly, for blood antioxidant potential, there was a time effect $(P=0.026)$, with an elevation at $\operatorname{IPE}(P=0.003)$ that returned to pre-exercise values by $90-\mathrm{P}(P=0.06)$.

The secondary PF data are presented in Table 4. For FVC, there was no interaction $(P=0.700)$, trial $(P=0.632)$, or time effect $(P=0.555)$. Similarly, $\mathrm{FEV}_{1}$ and 
Table 3. Variables of oxidative stress

\begin{tabular}{|c|c|c|c|c|}
\hline \multirow[t]{2}{*}{ Marker } & Filtered air trial & Woodsmoke trial & \multirow{2}{*}{$\begin{array}{c}\text { Main effect } \\
P\end{array}$} & \multirow{2}{*}{$\begin{array}{c}\text { Interaction effect } \\
P\end{array}$} \\
\hline & \multicolumn{2}{|c|}{$M e a n \pm S D$} & & \\
\hline \multicolumn{5}{|c|}{ Protein carbonyl $\left(\mathrm{nmol} \cdot \mathrm{mg}^{-1}\right)$} \\
\hline PRE & $0.18 \pm 0.03$ & $0.17 \pm 0.02$ & 0.505 & 0.699 \\
\hline IPE & $0.20 \pm 0.03$ & $0.17 \pm 0.02$ & & \\
\hline $90-\mathrm{P}$ & $0.18 \pm 0.03$ & $0.17 \pm 0.02$ & & \\
\hline \multicolumn{5}{|c|}{ 3-Nitrotyrosine $\left(\mu \mathrm{g} \cdot \mathrm{mL}^{-1}\right)$} \\
\hline PRE & $3.4 \pm 2.1$ & $3.0 \pm 1.6$ & 0.426 & 0.784 \\
\hline IPE & $3.8 \pm 2.4$ & $3.3 \pm 2.3$ & & \\
\hline $90-\mathrm{P}$ & $3.1 \pm 2.3$ & $2.8 \pm 1.6$ & & \\
\hline \multicolumn{5}{|c|}{ Lipid hydroperoxides $\left(\mu \mathrm{mol} \cdot \mathrm{L}^{-1}\right)$} \\
\hline PRE & $1.7 \pm 1.6$ & $3.3 \pm 1.6$ & $0.159^{\mathrm{a}}$ & 0.126 \\
\hline IPE & $2.5 \pm 2.1$ & $4.0 \pm 2.0$ & & \\
\hline $90-\mathrm{P}$ & $2.6 \pm 1.9$ & $3.2 \pm 2.1$ & & \\
\hline \multicolumn{5}{|c|}{ 8-Isoprostane $\left(\mathrm{pg} \cdot \mathrm{mL}^{-1}\right)$} \\
\hline PRE & $18.8 \pm 9.6$ & $22.2 \pm 12.2$ & 0.296 & 0.800 \\
\hline IPE & $24.9 \pm 12.5$ & $31.3 \pm 26.1$ & & \\
\hline $90-\mathrm{P}$ & $24.3 \pm 13.5$ & $28.8 \pm 23.6$ & & \\
\hline \multicolumn{5}{|c|}{ TEAC $\left(\mu \mathrm{mol} \cdot \mathrm{L}^{-1}\right)$} \\
\hline PRE & $112.7 \pm 12.3$ & $109.9 \pm 10.4$ & 0.068 & 0.234 \\
\hline IPE & $135.5 \pm 14.8$ & $118.4 \pm 19.8$ & & \\
\hline $90-\mathrm{P}$ & $125.2 \pm 16.3$ & $120.9 \pm 16.4$ & & \\
\hline
\end{tabular}

90-P, 90 min postexercise; IPE, immediately after exercise; PRE, before exercise; TEAC, Trolox equivalent antioxidant capacity.

${ }^{\text {a }}$ Significant main effect.

$\mathrm{FEV}_{1} / \mathrm{FVC}$ exhibited no interaction $\left(\mathrm{FEV}_{1}: P=0.373\right.$; $\left.\mathrm{FEV}_{1} / \mathrm{FVC}: \quad P=0.464\right)$, trial $\left(\mathrm{FEV}_{1}: P=0.940 ; \quad \mathrm{FEV}_{1} /\right.$

\begin{tabular}{|c|c|c|}
\hline \multirow[t]{3}{*}{ Variable } & Woodsmoke trial & \multirow{2}{*}{$\begin{array}{c}\text { Filtered air trial } \\
n=10\end{array}$} \\
\hline & $n=10$ & \\
\hline & \multicolumn{2}{|c|}{$\overline{M e a n} \pm \overline{S D}$} \\
\hline \multicolumn{3}{|l|}{ FVC (L) } \\
\hline PRE & $5.07 \pm 0.28$ & $5.04 \pm 0.25$ \\
\hline IPE & $5.03 \pm 0.26$ & $5.10 \pm 0.25$ \\
\hline 90-P & $5.02 \pm 0.26$ & $5.07 \pm 0.25$ \\
\hline \multicolumn{3}{|l|}{$\mathrm{FEV}_{1}(\mathrm{~L})$} \\
\hline PRE & $4.03 \pm 0.21$ & $4.02 \pm 0.19$ \\
\hline IPE & $4.09 \pm 0.22$ & $4.05 \pm 0.21$ \\
\hline 90-P & $4.05 \pm 0.20$ & $4.09 \pm 0.20$ \\
\hline \multicolumn{3}{|c|}{$\mathrm{FEV}_{1} / \mathrm{FVC}(\%)$} \\
\hline PRE & $80 \pm 2$ & $80 \pm 2$ \\
\hline IPE & $81 \pm 2$ & $80 \pm 2$ \\
\hline 90-P & $81 \pm 2$ & $81 \pm 1$ \\
\hline \multicolumn{3}{|c|}{$\operatorname{MVV}\left(L \cdot \min ^{-1}\right)$} \\
\hline PRE & $146 \pm 12$ & $146 \pm 10$ \\
\hline IPE & $159 \pm 14$ & $159 \pm 10$ \\
\hline 90-P & $141 \pm 12$ & $149 \pm 11$ \\
\hline
\end{tabular}

90-P, 90 min postexercise; FVC, forced vital capacity; $\mathrm{FEV}_{1}$, forced expiratory volume in $1 \mathrm{~s}$; IPE, immediately after exercise; MVV, maximal voluntary ventilation; PRE, before exercise.
FVC: $P=0.694)$, or time effect $\left(\mathrm{FEV}_{1}: P=0.406 ; \mathrm{FEV}_{1} /\right.$ FVC: $P=0.723)$. MVV also demonstrated no interaction $(P=0.800)$, trial $(P=0.667)$, or time effect $(P=0.068)$.

\section{Discussion}

Long-term woodsmoke inhalation is damaging to the cardiovascular system, but the acute effects of smoke exposure are not well understood. Recreational exercisers, wildland firefighters, and persons with chronic outdoor exposure during wildfire season are at risk for long-term cardiovascular health consequences. ${ }^{8,9}$ Accordingly, using a laboratory-based pilot investigation, we examined the acute effects of exercise and woodsmoke-inhalation $\left(\mathrm{PM}_{2.5} 250 \mu \mathrm{g} \cdot \mathrm{m}^{-3}\right)$ on the primary variables of HRV, PWV, and oxidative stress. Indeed, inhalation of concentrated smoke $\left(250 \mu \mathrm{g} \cdot \mathrm{m}^{-3}\right)$ elicits inflammation and oxidative stress response known to be deleterious to cardiovascular health. ${ }^{9,16}$ Although chronic smoke inhalation is detrimental to long-term cardiovascular function, our acute physiologic (HRV, PWV) and biochemical blood markers of oxidative stress were not statistically different between the smoke inhalation and filtered air challenges. This unexpected finding highlights the scientific importance of identifying acute physiologic and biochemical metrics that may better 
inform the long-term consequences of woodsmoke inhalation. We interpret these negative findings to have been influenced by the experimental context in which the laboratory-based investigation was conducted, attributing potential causation to the following methodologic factors: 1) examination of a population-young, apparentlyhealthy subjects-presumably more resilient to this smoke inhalation challenge; 2) methodologic constraints (eg, sampling time points and selection of biochemical variables); 3) small sample size; and 4) insufficient dose, which did not capture perturbations due to smoke.

A key dependent variable of this investigation was HRV. Inability to maintain a high resting HRV, or exhibiting delayed rebound after exposure to a stressor, predicts an increased risk for mortality and sudden cardiac death. ${ }^{17}$ Previous longitudinal findings demonstrated decreased HRV in those regularly exposed to woodsmoke PM in occupational settings. ${ }^{7}$ Notably, depression of HRV after acute smoke inhalation signals problematic responses to reoccurring exposure. Accordingly, we examined HRV after a single woodsmoke challenge in apparently healthy research participants to examine the potential of declines in HRV that could inform recurrent exposures. Results indicated no statistically significant alterations existed for HRV (lnRMSSD, lnHF, lnLF, LF:HF) for up to $90 \mathrm{~min}$ after exposure, a finding that does not discount the deleterious effects of acute smoke inhalation. In contrast to our findings, HRV (SDNN, RMSSD, HFnu, and pNN50) was systematically reduced in 14 subjects after a 3-h intermittent exercise session with exposure at $\sim 300 \mu \mathrm{g} \cdot \mathrm{m}^{-3},{ }^{6}$ This divergent outcome may indicate that the duration of smoke exposure within the current study was insufficient to elicit changes, highlighting the need to identify a woodsmoke exposure (duration and/or $\mathrm{PM}_{2.5}$ concentration) threshold that perturbs cardiovascular function. Moreover, age, fitness level, and health status - and the duration of HRV assessment (eg, longer sampling periods) — should be examined. Previous work demonstrated that HRV is acutely depressed in woodsmoke-exposed elderly populations. ${ }^{18}$ Additionally, postexercise parasympathetic rebound is enhanced in fit and healthy populations, ${ }^{5}$ suggesting our sample may have exhibited preserved HRV as compared to a sedentary population. Given the disparate outcomes of this study compared to others, future investigations should consider longer-duration baseline and postintervention HRV analyses to confirm or refute the current findings.

PWV is predictive of elevated cardiovascular event risk, ${ }^{19}$ although prior studies have examined the effects of woodsmoke exposure on PWV with equivocal results. ${ }^{6,20}$ Our findings demonstrated that PWV was not statistically different after a 45-min exercise session in filtered air and woodsmoke exposure at $250 \mu \mathrm{g} \cdot \mathrm{m}^{-3}$, a finding that is similar to a prior investigation reporting negative PWV outcomes $1 \mathrm{~h}$ postexercise with an exposure at $1000 \mu \mathrm{g} \cdot \mathrm{m}^{-3} \cdot{ }^{20}$ However, PWV has been demonstrated to increase for up to $25 \mathrm{~min}$ after a $3-\mathrm{h}$ bout of exercise and an exposure of $300 \mu \mathrm{g} \cdot \mathrm{m}^{-3}$. Collectively, PWV may be more responsive to exposures between 1 and $3 \mathrm{~h}$ in duration. ${ }^{6,20,21}$ In support, a recent study examined the effects of woodsmoke exposure at 3 different concentrations $\left(100 \mu \mathrm{g} \cdot \mathrm{m}^{-3}, 250\right.$ $\mu \mathrm{g} \cdot \mathrm{m}^{-3}$, and $500 \mu \mathrm{g} \cdot \mathrm{m}^{-3}$ ) under resting conditions, finding that PWV was elevated $24 \mathrm{~h}$ after all exposures. ${ }^{21}$ The magnitude of the elevation was similar across all 3 concentrations, signifying that PWV may not respond to smoke in a dose-dependent manner.

AIx is an additional variable of arterial stiffness that is associated with elevated cardiovascular disease risk. ${ }^{22,23}$ Our data demonstrated that AIx was not statistically different between the smoke exposure and filtered air trials for this healthy population. Previous research indicated AIx was elevated at a slightly higher dose of $\mathrm{PM}_{2.5}(\sim 314$ $\mu \mathrm{g} \cdot \mathrm{m}^{-3}$ ) after $3 \mathrm{~h}$ of exposure with intermittent exercise ${ }^{6}$; however, this response was not replicated when intermittent exercise was performed for $1 \mathrm{~h}$ at a $\mathrm{PM}_{2.5}$ dose of $\sim 1000 \mu \mathrm{g} \cdot \mathrm{m}^{-3} .{ }^{20}$ Although these mixed findings cannot be explained currently, there is a proposed association between elevated oxidative stress and increased arterial stiffness, indicating they may occur in tandem. ${ }^{24}$ Therefore, the exercise or exposure may require a yet-to-be determined duration or intensity threshold to elicit a measurable change in arterial stiffness.

All postexercise oxidative stress variables were not statistically different between woodsmoke and filtered air exposures as examined at these selected time points in healthy research participants. Previous research has demonstrated that a 1.5 -h treadmill bout with woodsmoke exposure at $500 \mu \mathrm{g} \cdot \mathrm{m}^{-3}$ resulted in an elevation of 3-NT immediately after exercise, but did not rise with an exposure at $250 \mu \mathrm{g} \cdot \mathrm{m}^{-3} .{ }^{8}$ In agreement with prior work, the current study indicated no statistically significant elevation after $45 \mathrm{~min}$ of exercise and smoke $\left(250 \mu \mathrm{g} \cdot \mathrm{m}^{-3}\right)$, suggesting that 3-NT may respond in a dose-dependent manner. Moreover, our negative findings for PC are consistent with the previously mentioned study, where PC was also unaltered by woodsmoke exposure at both $250 \mu \mathrm{g} \cdot \mathrm{m}^{-3}$ and $500 \mu \mathrm{g} \cdot \mathrm{m}^{-3} .8$ Importantly, these negative findings do not negate the detrimental impact of smoke inhalation on protein damage markers. By extension, we may have simply missed the spike in $\mathrm{PC}$, as this marker has been shown to peak hours or days after the stressor $^{25,26}$; thus, the selected sampling time points used currently may not have captured the peak response. 
Lipid oxidative damage was quantified via plasma LOOH and 8-ISO. Previous research demonstrated no elevation of $\mathrm{LOOH}$ after a 1.5 -h woodsmoke exposure during low-intensity exercise ${ }^{8}$; however, 8-ISO was elevated immediately after exercise at 2 inhalation doses $\left(250 \mu \mathrm{g} \cdot \mathrm{m}^{-3}\right.$ and $\left.500 \mu \mathrm{g} \cdot \mathrm{m}^{-3}\right)$. Moderate-intensity exercise $\left(70 \% \dot{\mathrm{V}}_{2}\right.$ max cycling) was selected currently to elevate ventilatory rates; however, $\mathrm{LOOH}$ and 8-ISO were not statistically different after exercise with $\mathrm{PM}_{2.5}=250 \mu \mathrm{g} \cdot \mathrm{m}^{-3}$. Nonetheless, $\mathrm{LOOH}$ is most responsive to high-intensity exercise, ${ }^{27}$ suggesting that our exercise modality and $\mathrm{PM}_{2.5}$ dose were insufficient to elicit elevations.

TEAC was also examined after exercise and woodsmoke exposure; however, it was not statistically different between woodsmoke and filtered air exposures. Previous work examined the TEAC response to higher woodsmoke exposure (average $375 \mu \mathrm{g} \cdot \mathrm{m}^{-3}$ ) during a 1.5$\mathrm{h}$ bout of treadmill walking and found TEAC was elevated in response to woodsmoke exposure. ${ }^{8}$ However, when the prior $250 \mu \mathrm{g} \cdot \mathrm{m}^{-3}$ exposure trial was examined alone, TEAC was not elevated in response to the exposure, in agreement with our TEAC values after a 45-min exposure at $250 \mu \mathrm{g} \cdot \mathrm{m}^{-3}$. These collective findings indicate that TEAC may be responsive to woodsmoke exposure in a dose-dependent manner. Overall, we did not observe a statistically significant increase in postexercise oxidative stress markers between smoke inhalation and filtered air, which suggests that these markers respond differently based on exposure dose and duration, in addition to exercise intensity. We interpret this finding to indicate that our methodologic approach (eg, exercise dose, population, and sampling time points) did not elicit oxidative changes, a finding that would have otherwise been present in multiple markers across our oxidative stress panel.

$\mathrm{PF}$ was examined as a secondary group of variables in our healthy sample population. Findings indicated that $\mathrm{FVC}, \mathrm{FEV}_{1}$, and MVV were not statistically different for either exercise or exposure. Importantly, these findings are consistent with previous work that demonstrated no changes in FVC, $\mathrm{FEV}_{1}$, or MVV after a 1.5 -h exposure during treadmill walking ${ }^{9}$ and highlights the fact that although smoke inhalation is clearly detrimental to longterm health ${ }^{28}$ acute physiologic responses to exposure may not always result.

\section{LIMITATIONS}

Study limitations include the nature and size of the sample. Owing to the age range, fitness level, and overall health of the examined sample, inferences that can be drawn from these results are limited proportionately. Thus, it is plausible that these methods, if applied to more susceptible populations (eg, age, chronic conditions), may have produced alternative outcomes for our grouped outcome measures of HRV, PWV metrics, and oxidative stress markers. Furthermore, female participants were underrepresented within this study $(n=3)$ and the potential confounding influence of hormonal alterations (eg, menstrual cycle or contraceptive use) was not considered. For this reason, conclusions about female-specific responses cannot be drawn from the results of the current study. Furthermore, the dose of woodsmoke exposure may been insufficient to elicit adverse effects on the selected variables. The study design was predicated on the notion that a 7-d washout period is sufficient for the assessment of acute physiologic responses to smoke exposure, an assumption that should be confirmed with future investigations. Additionally, the study examined only 1 modality, duration, and intensity of exercise, limiting the application of these findings to similar exercise.

\section{Conclusions}

Chronic woodsmoke exposure is linked to negative health effects on cardiovascular control and oxidative stress, although the influence of acute smoke inhalation effects are not well defined. The current study quantified the acute effects of $45 \mathrm{~min}$ of exercise during woodsmoke exposure $\left(250 \mu \mathrm{g} \cdot \mathrm{m}^{-3}\right)$ on markers of $\mathrm{HRV}$, arterial stiffness, and oxidative stress; however, there were no statistically significant differences observed as compared to filtered air. Given the undeniable link between chronic smoke inhalation and cardiovascular health, we interpret the negative findings of the current study to have been limited by the experimental context in which the laboratory-based study was conducted. Future research should examine the threshold for duration, dose, and/or frequency of smoke exposure needed to produce acute perturbation in these parameters. Moreover, the health and fitness status of the investigated population may alter the exposure thresholds, meaning that participant age, training status, medical conditions, and sex-dependent differences should also be considered in future study designs.

Author Contributions: Study concept and design (JCQ, CLD); acquisition of data (CWR, KT, DR, KC, SG, KW, TQ); analysis of data (CWR, KC, SG, TQ); drafting of the manuscript (CWR, JCQ); critical revision of the manuscript (CWR, JCQ, KT, KC, SG, CLD); approval of the final manuscript (all authors).

Financial/Material Support: The funding for the investigation was provided by a USDA Forest Service grant $18-\mathrm{CR}-11138100-023$ to JCQ.

Disclosures: None. 


\section{References}

1. Cascio WE. Wildland fire smoke and human health. Sci Total Environ. 2018;624:586-95.

2. Adetona O, Reinhardt TE, Domitrovich J, Broyles G, Adetona AM, Kleinman MT, et al. Review of the health effects of wildland fire smoke on wildland firefighters and the public. Inhal Toxicol. 2016;28(3):95-139.

3. Löndahl J, Massling A, Pagels J, Swietlicki E, Vaclavik E, Loft S. Size-resolved respiratory-tract deposition of fine and ultrafine hydrophobic and hygroscopic aerosol particles during rest and exercise. Inhal Toxicol. 2007;19(2):109-16.

4. Brook RD, Rajagopalan S, Pope III CA, Brook JR, Bhatnagar A, Diez-Roux AV, et al. Particulate matter air pollution and cardiovascular disease: An update to the scientific statement from the american heart association. Circulation. 2010;121(21): 2331-78.

5. Stanley J, Peake JM, Buchheit M. Cardiac parasympathetic reactivation following exercise: implications for training prescription. Sports Med. 2013;43(12):1259-77.

6. Unosson J, Blomberg A, Sandström T, Muala A, Boman C, Nyström R, et al. Exposure to wood smoke increases arterial stiffness and decreases heart rate variability in humans. Part Fibre Toxicol. 2013;10:20.

7. Magari SR, Hauser R, Schwartz J, Williams PL, Smith TJ, Christiani DC. Association of heart rate variability with occupational and environmental exposure to particulate air pollution. Circulation. 2001;104(9):986-91.

8. Peters B, Ballmann C, Quindry T, Zehner EG, McCroskey J, Ferguson M, et al. Experimental woodsmoke exposure during exercise and blood oxidative stress. J Occup Environ Med. 2018;60(12):1073-81.

9. Ferguson MD, Semmens EO, Dumke C, Quindry JC, Ward TJ. Measured pulmonary and systemic markers of inflammation and oxidative stress following wildland firefighter simulations. J Occup Environ Med. 2016;58(4):407-13.

10. Warburton DE, Jamnik VK, Bredin SS, Gledhill N. The physical activity readiness questionnaire for everyone (PAR-Q+) and electronic physical activity readiness medical examination (ePARmedX+). Health Fit J. 2011;4(2):3-17.

11. Siri WE Body composition from fluid spaces and density: analysis of methods. Techniques for measuring body composition. National Academy of Sciences National Research Council. Washington, D. C. 1961:223-44.

12. Task Force of the European Society of Cardiology the North American Society of Pacing Electrophysiology. Heart rate variability, standards of measurement, physiological interpretation, and clinical use. Circulation. 1996;93(5): 1043-65.

13. Erel O. A novel automated direct measurement method for total antioxidant capacity using a new generation, more stable abts radical cation. Clin Biochem. 2004;37(4):277-85.
14. Nourooz-Zadeh J. Ferrous ion oxidation in presence of xylenol orange for detection of lipid hydroperoxides in plasma. Methods Enzymol. 1999;300:58-62.

15. Bradford MM. A rapid and sensitive method for the quantitation microgram quantities of a protein isolated from red cell membranes. Anal Biochem. 1976;72:248-54.

16. Peters B, Ballmann C, Mcginnis G, Epstein E, Hyatt H, Slivka D, et al. Graded hypoxia and blood oxidative stress during exercise recovery. J Sports Sci. 2016;34(1):56-66.

17. Kamath MV, Watanabe M, Upton A. Heart rate variability (hrv) signal analysis: clinical applications. Boca Raton, FL: CRC Press; 2012.

18. Devlin R, Ghio A, Kehrl H, Sanders S, Cascio W. Elderly humans exposed to concentrated air pollution particles have decreased heart rate variability. Eur Respir J Suppl. 2003;40:76s-80s.

19. Van Bortel LM, Laurent S, Boutouyrie P, Chowienczyk P, Cruickshank J, De Backer T, et al. Expert consensus document on the measurement of aortic stiffness in daily practice using carotidfemoral pulse wave velocity. J Hypertens. 2012;30(3):445-8.

20. Hunter AL, Unosson J, Bosson JA, Langrish JP, Pourazar J, Raftis JB, et al. Effect of wood smoke exposure on vascular function and thrombus formation in healthy fire fighters. Part Fibre Toxicol. 2014;11:62.

21. Walker ES, Fedak KM, Good N, Balmes J, Brook RD, Clark ML, et al. Acute differences in pulse wave velocity, augmentation index, and central pulse pressure following controlled exposures to cookstove air pollution in the subclinical tests of volunteers exposed to smoke (SToVES) study. Environ Res. 2020;180:108831.

22. Nürnberger J, Keflioglu-Scheiber A, Saez AMO, Wenzel RR, Philipp T, Schäfers RF. Augmentation index is associated with cardiovascular risk. J Hypertens. 2002;20(12):2407-14.

23. Wilkinson IB, Fuchs SA, Jansen IM, Spratt JC, Murray GD, Cockcroft JR, et al. Reproducibility of pulse wave velocity and augmentation index measured by pulse wave analysis. J Hypertens. 1998;16(12 Pt 2):2079-84.

24. Gaughan DM, Siegel PD, Hughes MD, Chang CY, Law BF, Campbell CR, et al. Arterial stiffness, oxidative stress, and smoke exposure in wildland firefighters. Am $J$ Ind Med. 2014;57(7):748-56.

25. Hudson MB, Hosick PA, McCaulley GO, Schrieber L, Wrieden J, McAnulty SR, et al. The effect of resistance exercise on humoral markers of oxidative stress. Med Sci Sports Exerc. 2008;40(3):542-8.

26. Bloomer RJ, Goldfarb AH, Wideman L, McKenzie MJ, Consitt LA. Effects of acute aerobic and anaerobic exercise on blood markers of oxidative stress. J Strength Cond Res. 2005;19(2):276-85.

27. Alessio HM, Hagerman AE, Fulkerson BK, Ambrose J, Rice RE, Wiley RL. Generation of reactive oxygen species after exhaustive aerobic and isometric exercise. Med Sci Sports Exerc. 2000;32(9):1576-81.

28. Jacquin L, Michelet P, Brocq FX, Houel JG, Truchet X, Auffray JP, et al. Short-term spirometric changes in wildland firefighters. Am J Ind Med. 2011;54(11):819-25. 